\title{
Investigation of role of cartilage surface polymer brush border in lubrication of biological joints
}

\author{
JinJing LIAO ${ }^{1}$, David W. SMITH ${ }^{2}$, Saeed MIRAMINI ${ }^{1}$, Bruce S. GARDINER ${ }^{3}$, Lihai ZHANG ${ }^{1, *}$ \\ ${ }^{1}$ Department of Infrastructure Engineering, The University of Melbourne, Victoria 3010, Australia \\ ${ }^{2}$ Faculty of Engineering and Mathematical Sciences, The University of Western Australia, WA 6009, Australia \\ ${ }^{3}$ College of Science, Health, Engineering and Education, Murdoch University, WA 6150, Australia \\ Received: 16 July 2020 / Revised: 03 October 2020 / Accepted: 29 October 2020 \\ (C) The author(s) 2020 .
}

\begin{abstract}
Although experimental evidence has suggested that the polymer brush border (PBB) on the cartilage surface is important in regulating fluid permeability in the contact gap, the current theoretical understanding of joint lubrication is still limited. To address this research gap, a multiscale cartilage contact model that includes $\mathrm{PBB}$, in particular its effect on the fluid permeability of the contact gap, is developed in this study. Microscale modeling is employed to estimate the permeability of the contact gap. This permeability is classified into two categories: For a gap size $>1 \mu \mathrm{m}$, the flow resistance is assumed to be dominated by the cartilage roughness; for gap size $<1 \mu \mathrm{m}$, flow resistance is assumed to be dominated by the surface polymers extending beyond the collagen network of the articular cartilage. For gap sizes of less than $1 \mu \mathrm{m}$, the gap permeability decreases exponentially with increasing aggrecan concentration, whereas the aggrecan concentration varies inversely with the gap size. Subsequently, the gap permeability is employed in a macroscale cartilage contact model, in which both the contact gap space and articular cartilage are modeled as two interacting poroelastic systems. The fluid exchange between these two media is achieved by imposing pressure and normal flux continuity boundary conditions. The model results suggest that PBB can substantially enhance cartilage lubrication by increasing the gap fluid load support (e.g., by 26 times after a 20-min indentation compared with the test model without a PBB). Additionally, the fluid flow resistance of PBB sustains the cartilage interstitial fluid pressure for a relatively long period, and hence reduces the vertical deformation of the tissue. Furthermore, it can be inferred that a reduction in the PBB thickness impairs cartilage lubrication ability.
\end{abstract}

Keywords: articular cartilage; polymer brush border; cartilage surface roughness; permeability of cartilage contact gap; fluid load support in cartilage contact gap

\section{Introduction}

Articular cartilage is a biological tissue located in the diarthrodial joints of vertebrate animals. It encompasses the ends of long bones in a synovial fluid-filled lined cavity. Although articular cartilage is only $2-4 \mathrm{~mm}$ thick, it can sustain extreme biomechanical conditions. For example, in knee joints, cartilage must withstand a vertical load up to three times the body weight during walking [1] while having a remarkably low initial coefficient of friction, on the order of 0.01 [2]. For comparison, even the best-manufactured bearing (e.g., Teflon) can only achieve a coefficient of friction 0.05-0.08 under a 3.4 MPa static load [2].

In addition to earlier lubrication theories (e.g., weeping [3] and boosted lubrication [4]), the concept

* Corresponding author: Lihai ZHANG, E-mail: lihzhang@unimelb.edu.au 
of "hydration lubrication" $[5,6]$ is delved to the effects on cartilage tribological performance of the "surface amorphous layer" [7], which includes polymer brushes tethered to the cartilage surface. As shown in Fig. 1, cartilage comprises chondrocytes and an extracellular matrix (proteoglycan and type II collagen), exhibiting a zonal structure throughout its thickness $[8,9]$. Cartilage surface roughness is formed by bundles of collagen fibrils within the superficial zone [9]. The reported roughness heights depend on the length scale at which they are measured. For example, in the normal human knee cartilage, for small length scales of 1-2 $\mu \mathrm{m}$, asperities are small and measured in tens of nanometers, whereas, for the typical contact measurement length scale exceeding $500 \mu \mathrm{m}$, the reported roughness heights are relatively consistent, i.e., 5-10 $\mu \mathrm{m}$ [9]. Most importantly, transmission electron microscopy images revealed that an acellular, non-collagenous amorphous layer appeared on top of collagen fibrils [10]. The tethered layer within the amorphous layer was formed by polymers embedded in the cartilage surface extending beyond the collagen fibril defined surface. The polymers included molecules such as hyaluronan (HA), aggrecan (GAG), lubricin, phospholipids, and various other proteins [11], which formed a "polymer brush border (PBB)" on the cartilage surface. The thickness of this PBB was in the range of $200 \mathrm{~nm}$ (approximately the height of a single lubricin molecule [12]) to a few microns, varying with species, the joint type, or the age [13]. It is known that the negative fixed charge density of GAG molecules provides resistance to fluid flow in articular cartilage [14]; therefore, the authors postulated that PBB tethered to the surface of articular cartilage might reduce the permeability in the contact gap to lateral fluid flow. This reduced permeability might affect cartilage lubrication. It is hypothesized that the negatively charged polymers on the cartilage surface may support large contact stresses without being salvaged out of the gap (unlike the remainder of the amorphous layer) because these polymers are tethered to the cartilage surface $[15,16]$.

Evidence supporting the idea that PBB may be important in joint lubrication has been reported in several recent experimental studies. For example, it was observed that the selective digestion of HA and GAG increased the friction force on cartilage samples by 2 and 10 times, respectively [17]. In addition, the initial friction coefficients for cartilage samples with PBB removed were higher than those of intact samples [18]. However, our current theoretical understanding regarding the roles of PBB in cartilage lubrication is still limited.

Most cartilage lubrication models are typically formulated based on the assumption of a perfectly smooth surface [19]. This assumption disregards both the effect of surface roughness and the "contact gap space", which is created between opposing surfaces as surface asperities begin to form contact with one another (i.e., when surface asperities are in contact initially, the gap size in the normal human knee cartilage is $h=10-20 \mu \mathrm{m}$, i.e., approximately twice the roughness height for cartilage-on-cartilage contact [9]).

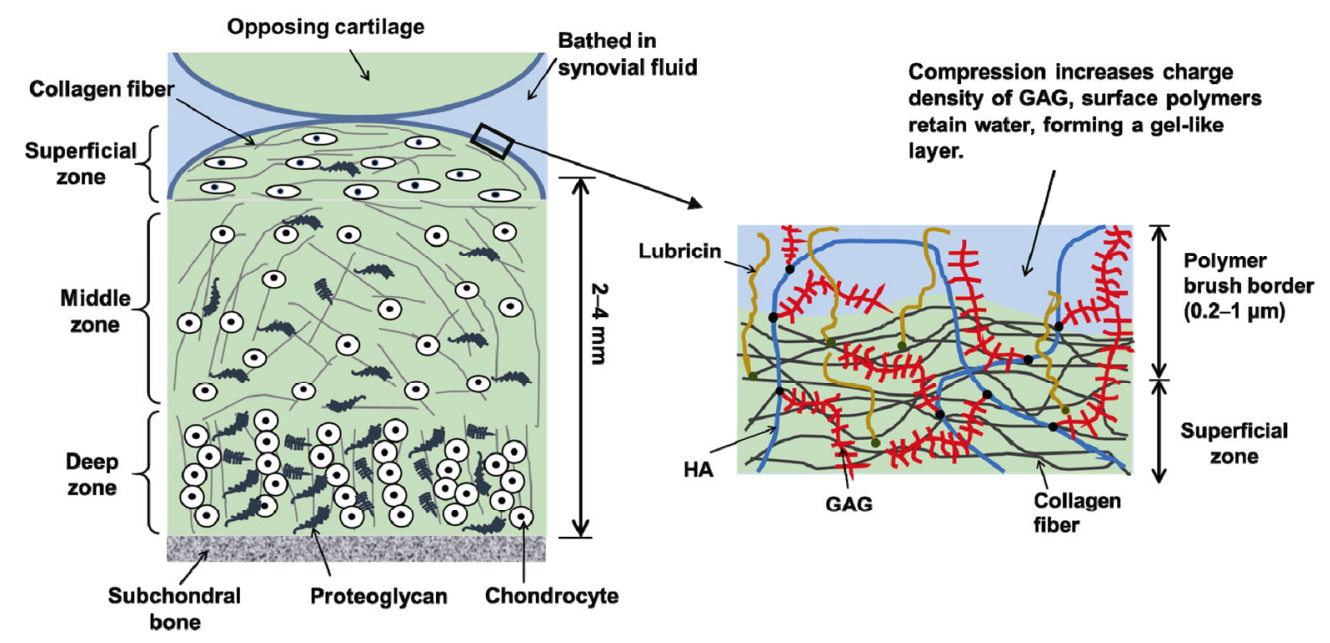

Fig. 1 Schematic diagram showing details of cartilage structure and surface. 
A recent coupled contact model developed by the authors was used to investigate cartilage lubrication in the mixed-mode regime (i.e., considering the surface roughness and contact gap space). This model revealed that interstitial fluid exuded from cartilage tissue into the contact gap by asperity contact significantly extended the mixed-mode duration [20]. However, the viscosity of the interstitial fluid exuded from the underlying cartilage into the gap was relatively low (approximately that of water, i.e., $\sim 0.001 \mathrm{~Pa} \cdot \mathrm{s}$ ). Therefore, the viscosity of the support fluid would presumably be decrease as synovial fluid is diluted by the exudate from the articular cartilage. When the viscosities of synovial fluid are in the range of 0.01-0.1 Pa's (corresponding to the shear rates of physiological activities of $10^{2}-10^{4} \mathrm{~s}^{-1}$ [21]), the simulation results of the coupled contact model [20] suggested that the gap fluid pressure could be sustained for only a relatively short time compared with the experimentally measured times for cartilage consolidation. These modeling results suggest that our initial contact model is incomplete; hence, we performed further investigations.

The focus of this study was to investigate the possible role of PBB in cartilage lubrication. Specifically, we hypothesized that for narrow contact gap sizes, PBB could potentially provide sufficient resistance to the exudate fluid flow to maintain the fluid pressure in the contact gap for a duration that represented a significant fraction of the consolidation time of articular cartilage (on the order of $1 \mathrm{~h}$ ).

Although a previous study [22] attempted to model surface polymers as a second softer biphasic tissue on top of cartilage, the permeability of the soft layer was not assessed (it was simply assumed to be the same as that of the cartilage tissue). In this study, more sophisticated models were developed to accurately evaluate the permeability at the contact interface. The modeling involves dividing the contact gap into two layers and establishing two sets of nonlinear relationships between gap permeability and gap size in their respective layers as the contact persists. By assuming that the thickness of PBB is approximately $1 \mu \mathrm{m}[23,24]$, we hypothesized that for gap sizes $>1 \mu \mathrm{m}$, fluid flow was primarily resisted by the surface roughness obstruction effect with a viscous synovial fluid and that the contact gap permeability could be estimated using a microscale computational fluid dynamics (CFD) model. Meanwhile, for gap sizes $<1 \mu \mathrm{m}$, we assumed that the contact gap permeability was dominated by the charged polymers tethered to the cartilage surface, the gap permeability was decreased exponentially with GAG concentration, and the GAG concentration varied inversely with the gap size. With the contact gap permeability estimated for all gap sizes, this permeability was then employed in a macroscale cartilage contact model, in which both the contact gap and cartilage tissue were modeled as two interacting poroelastic systems. The fluid exchange between these two systems was achieved by imposing pressure and flux continuity boundary continuity conditions. The numerical procedure adopted in this study is depicted schematically in Fig. 2.

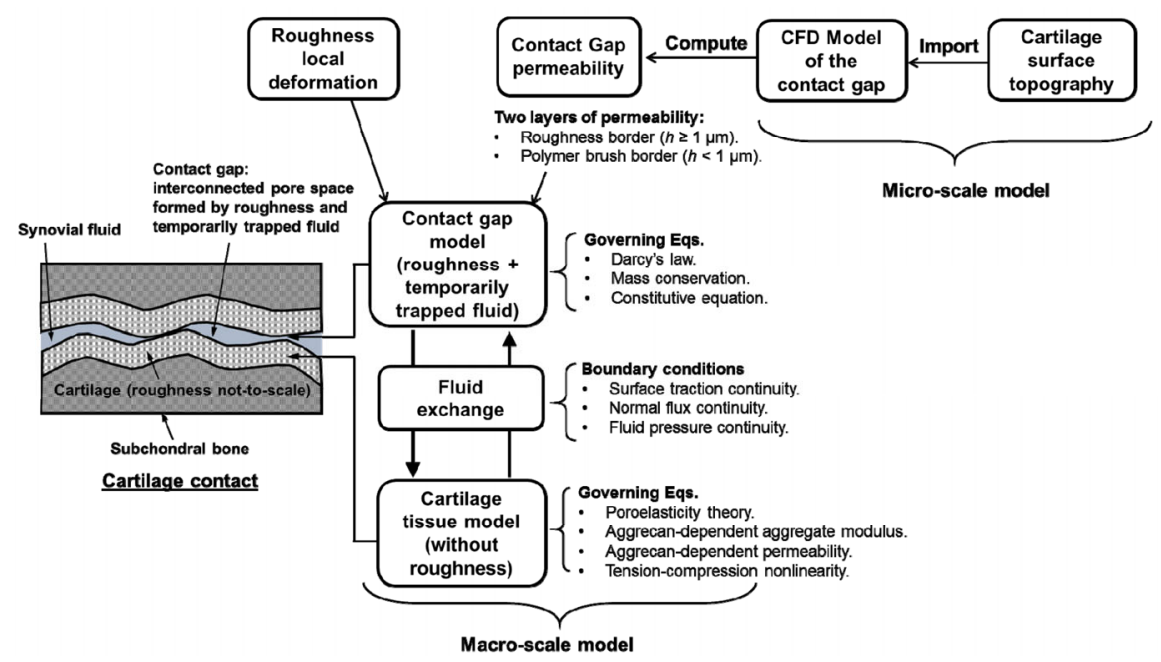

Fig. 2 Numerical procedure of cartilage contact model. 
Next, we described the methods in more detail, specifically the development of our multiscale mathematical model and its numerical solution. Subsequently, we compared the model predictions of important gaps and tissue parameters in the presence and absence of PBB. In a series of parametric studies, we evaluated the effects of the initial gap size, viscosity of synovial fluid, and thickness of PBB on cartilage lubrication. Based on these studies, we concluded that PBB is crucial to the lubrication of normal synovial joints.

\section{Materials and methods}

\subsection{Overview of this study}

A theoretical model was developed in this study to investigate the role of PBB in cartilage lubrication. As a case study to test the hypothesis that the loading of PBB significantly affects the gap fluid pressure and its duration, and in vitro indentation on a large cartilage disc was simulated computationally. As shown in Fig. 3(a), an unconfined compression experiment was simulated in the model. The model geometry was simplified to be axisymmetric, representing an explant obtained from one of the tibial and femoral condyles. During the numerical experiment, the cartilage disc was immersed in synovial fluid and vertically compressed for $1 \mathrm{~h}$ by a rigid, impermeable, perfectly smooth indenter. On the indenter, a uniformly distributed quasistatic load at $\sigma_{\mathrm{t}}=1 \mathrm{MPa}$ (i.e., $314 \mathrm{~N}$ ) was applied. The simulation began when the indenter established contact with the highest asperity of the cartilage surface (i.e., at the onset of the mixed-mode lubrication). As depicted by the microscopic view shown in Fig. 3(b), once contact was initiated, an interconnected pore space (termed the "contact gap") was formed. The initial gap size

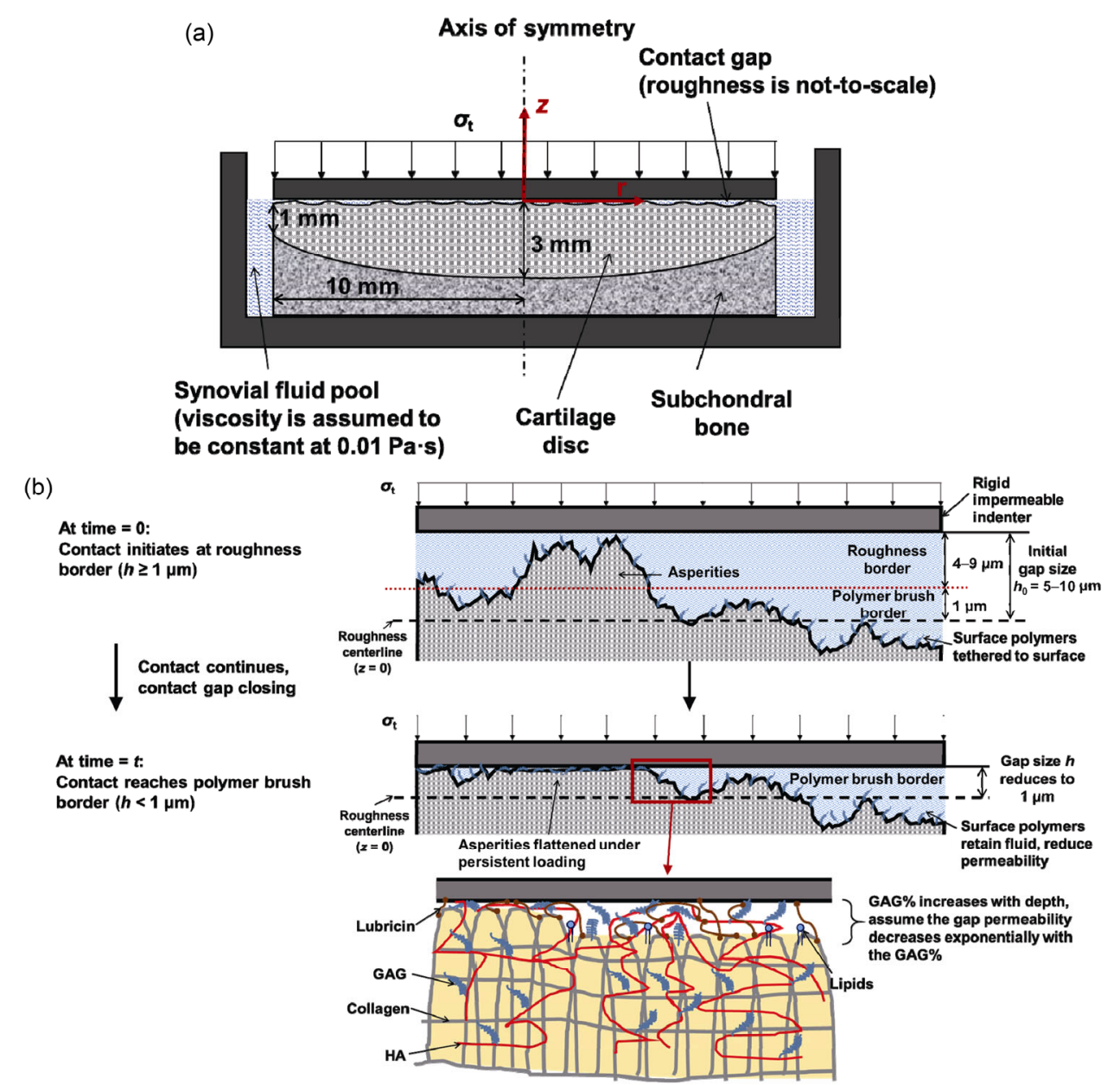

Fig. 3 Cartilage contact problem investigated in this study: (a) model geometry and problem configuration; (b) microstructure of the contact gap under indentation. 
$h_{0}$ was equal to the peak asperity height $R_{\mathrm{p}}$ of the surface roughness (5-10 $\mu \mathrm{m}$ [9]). Under a persistent and constant load, the gap reduced gradually as the consolidation of the cartilage tissue progressed. This gap closure is described by the gap height $h$, where $h \leqslant h_{0}$.

The fluid flow in the contact gap was governed by Darcy's law, and the permeability was dependent on the gap size. When the gap height $h$ was greater than $1 \mu \mathrm{m}$, the asperities provided resistance to radial flow in the gap, with flow resistance primarily originating from the roughness obstruction owing to the viscous drag of synovial fluid flowing around the asperities. However, when $h$ was less than $1 \mu \mathrm{m}$, the surface-tethered polymer brushes occupied most of the contact gap, and PBB was assumed to contribute primarily to the radial flow resistance.

The permeability of PBB was dependent on the GAG concentration in the gap [25]. As the GAGs protruded into gaps or were bound to HA protruding from the cartilage surface [11], the actual spatial variation of the GAG concentration was expected to vary with distance from the cartilage surface into the gap space. To estimate the gap permeability due to PBB, we identified the constraints that bounded its magnitude. Hence, we first assumed that the switch in the primary source of permeability that occurred at $h=1 \mu \mathrm{m}$ was continuous. Next, we assumed that as $h \rightarrow 0$, the permeability in the contact gap approached the permeability of the underlying cartilage tissue. Finally, between these two bounding permeabilities, we assumed that the logarithm of the gap permeability was decreased linearly with the gap size. Based on these assumptions, we can define the permeability in PBB at all times when $h$ is less than $1 \mu \mathrm{m}$.

Some additional key assumptions employed in the model were as follows:

For simplicity, in this analysis, it is assumed that the viscosity of synovial fluid remains constant at $0.01 \mathrm{~Pa} \cdot \mathrm{s}$ during indentation. However, the viscosity of synovial fluid is, in fact, shear rate dependent (0.01 Pa.s corresponds to a shear rate $>1,000 \mathrm{~s}^{-1}$ [26]);

As described in our previous study [20], the model assumes an exponential constitutive equation exists that can describe the relationship between gap closure and contact stress.

\subsection{Governing equations}

\subsubsection{Cartilage tissue model}

The cartilage tissue model adopted in this study was established within the poroelastic framework $[27,28]$. Three primary features of the extracellular matrix (i.e., GAG-dependent permeability, GAGdependent compressive modulus, and tensioncompression nonlinearity) were incorporated in the model. Zhang et al. [29] validated this cartilage tissue model against experimental measurements [30]. This cartilage model is summarized below.

It is assumed that the cartilage tissue spatially overlaps a combination of a solid matrix and a fluid phase [31]. Based on poroelasticity theory, the fluid flow in the cartilage tissue is governed by Darcy's law as follows:

$$
\boldsymbol{v}_{\mathrm{d}}^{\mathrm{c}}=\phi^{\mathrm{f}}\left(\boldsymbol{v}^{\mathrm{f}}-\boldsymbol{v}^{\mathrm{s}}\right)=-K_{\mathrm{c}} \nabla p_{\mathrm{c}}
$$

where $v_{\mathrm{d}}^{\mathrm{c}}$ is the Darcy's velocity inside the cartilage tissue, $\phi^{\mathrm{f}}=0.8$ is the fluid volume fraction, $v^{\mathrm{f}}$ and $\boldsymbol{v}^{\mathrm{s}}$ are the true velocity vectors of the fluid and solid phases, respectively, $K_{\mathrm{c}}$ is the permeability tensor of the cartilage tissue, and $p_{\mathrm{c}}$ is the excess interstitial fluid pressure.

The continuity equation of the solid and fluid phases in the biphasic media can be expressed as [32]

$$
\nabla \cdot\left(\phi^{\mathrm{s}} \boldsymbol{v}^{\mathrm{s}}+\phi^{\mathrm{f}} \boldsymbol{v}^{\mathrm{f}}\right)=0
$$

where and $\phi^{s}=0.2$ is the solid volume fraction [33]. In this study, it was assumed that the cartilage tissue experienced a small deformation; therefore, a constant fluid and a solid volume fraction were adopted in the formulation.

The conservation of momentum equation for the cartilage tissue is expressed as

$$
\nabla \cdot \sigma_{\mathrm{t}}=0
$$

where $\sigma_{\mathrm{t}}$ is the total applied stress tensor, which is the sum of the solid matrix stress $\sigma^{\text {s }}$ and fluid stress $\sigma^{\mathrm{f}}$ in the tissue.

$$
\sigma_{\mathrm{t}}=\boldsymbol{\sigma}^{\mathrm{s}}+\boldsymbol{\sigma}^{\mathrm{f}}=\boldsymbol{\sigma}_{\mathrm{E}}^{\mathrm{s}}-p_{\mathrm{c}} \boldsymbol{I}
$$

where $\sigma_{\mathrm{E}}^{\mathrm{s}}$ is the incremental effective stress due to the deformation of the solid phase, and $I$ is the identity tensor.

In this study, it could be reasonably assumed that the cartilage tissue experiences negligible rotations 
as the cartilage was deformed by a rigid indenter. In this case, an infinitesimal strain formulation could be used to simulate the mechanical behavior of the cartilage. A nonlinear elastic material model was developed to simulate the stress-stiffening behavior of cartilage under tension and compression.

Cartilage is anisotropic and inhomogeneous, exhibiting tension-compression nonlinearity. The compressive stiffness in the model was governed by a nonlinear deformation-dependent GAG concentration, whereas, the tensile stiffness was regulated by the collagen volume fraction and direction. The details of the constitutive model are described below.

Experimental results suggested that the cartilage tissue permeability $K_{\mathrm{c}}$ was dependent on the GAG concentration [25]. In this study, $K_{\mathrm{c}}$ was assumed to be isotropic and can be obtained by calibration with experimental observations as follows [25]:

$$
K_{\mathrm{c}}=\frac{n \cdot\left(c_{\mathrm{agg}}^{\mathrm{c}}\right)^{m}}{\eta_{\mathrm{c}}}
$$

where $n=5.4 \times 10^{-22} \mathrm{~m}^{2}$ and $m=-2.37$ are empirical parameters obtained from a previous study [33], $\eta_{c}$ is the viscosity of the interstitial fluid $(0.0007 \mathrm{~Pa} \cdot \mathrm{s})$ and $c_{\text {agg }}^{c}$ is the actual GAG concentration in the cartilage tissue.

It is noteworthy that the actual GAG concentration (i.e., milligrams of $\mathrm{GAG} / \mathrm{mL}$ of extrafibrillar volume) was higher than the apparent GAG concentration (i.e., milligrams of $\mathrm{GAG} / \mathrm{mL}$ of cartilage tissue). Miramini et al. [33] explained this difference. The relationship is expressed as follows:

$$
c_{\mathrm{agg}}^{\mathrm{c}}(t)=\frac{c_{\mathrm{agg}, 0}^{\mathrm{c}}}{J^{\mathrm{s}}(t)-\xi}
$$

where $c_{\mathrm{agg}, 0}^{\mathrm{c}}$ is the initial apparent GAG concentration, $\xi$ is the volume fraction of the collagen network, which is approximately equivalent to the solid volume fraction of the tissue (i.e., $45 \%$ in superficial zone, $30 \%$ in middle zone, $25 \%$ in deep zone [33]), $J^{\mathrm{s}}(t)$ is the volumetric change of the solid phase, which is equal to the Jacobian determinant of the deformation gradient of the solid phase $F^{\text {S }}$ (i.e., $J^{\mathrm{s}}(t)=\operatorname{det}\left(\boldsymbol{F}^{\mathrm{s}}\right)$. Furthermore, the GAG concentration was inhomogeneously distributed throughout the cartilage depth. The measured apparent GAG concentration was the lowest in the superficial zone (approximately $25 \mathrm{mg} / \mathrm{mL}$ at the tissue surface) and increased linearly with the depth to approximately $120 \mathrm{mg} / \mathrm{mL}$ in the deep zone [34]. Therefore, in this study, $\quad c_{\text {agg }}^{c}=25$ and $120 \mathrm{mg} / \mathrm{mL}$ were adopted at $z=0$ and $-3 \mathrm{~mm}$, respectively, and the values in between were obtained by linear interpolation. The permeability computed at the tissue surface $K_{\mathrm{c}}$ $(z=0 \mathrm{~mm})$ was $5 \times 10^{-15} \mathrm{~m}^{2} /(\mathrm{Pa} \cdot \mathrm{s})$, which is within the range of typical values measured from healthy cartilage samples $\left(0.5 \times 10^{-15}-8 \times 10^{-15} \mathrm{~m}^{2} /(\mathrm{Pa} \cdot \mathrm{s})[35]\right)$.

The aggregate modulus $\left(H_{-\mathrm{A}}\right)$ was dependent on the GAG concentration. It has been experimentally demonstrated that the aggregate modulus at the equilibrium state was increased with GAG content and decreased with increasing water content [36]. A quadratic equation has been proposed to capture the relationship between the actual GAG concentration $\left(c_{\mathrm{agg}}^{\mathrm{c}}\right)$ and the aggregate modulus [29].

$$
H_{-\mathrm{A}}=\alpha_{1} c_{\mathrm{agg}}^{\mathrm{c}}+\alpha_{2}\left(c_{\mathrm{agg}}^{\mathrm{c}}\right)^{2}
$$

Furthermore, the elastic compressive modulus of cartilage tissue $E_{\mathrm{c}}$ can be computed using Eq. (8) [9]:

$$
E_{\mathrm{c}}=3 H_{-\mathrm{A}}(1-2 v)
$$

where $\alpha_{1}=0.25 \mathrm{MPa}$ and $\alpha_{2}=0.0155 \mathrm{MPa}$ are empirical constants obtained from a previous study [33], and $v$ is the Poisson's ratio of the (drained) GAG matrix, typically set as zero [35].

The tensile and shear resistance of the cartilage were provided by the collagen network, and the moduli were dependent on the collagen volume fraction, which varied with the cartilage zones. The cartilage tissue was partitioned into three zones along with the depth: the "superficial zone" (SZ, 5\% of cartilage thickness), the "middle zone" (MZ, 45\% of the cartilage thickness), and the remaining "deep zone" (DZ). For simplicity, constant tensile and shear moduli were adopted in this study. Following Miramini et al. [33], the shear moduli are 3, 3, and $2 \mathrm{MPa}$ for $\mathrm{SZ}, \mathrm{MZ}$, and DZ respectively. The tensile moduli are different in two directions: (1) in $z$-axis, they are 25, 10, and $15 \mathrm{MPa}$ for SZ, MZ, and DZ, respectively; (2) in $r$-axis, they are 100,30 , and 10 $\mathrm{MPa}$ for SZ, MZ, and DZ, respectively [33].

\subsubsection{Contact gap model}

A contact gap model was proposed by Liao et al. [20]. 
In the current study, we extended this model by incorporating PBB into the contact gap model. The contact gap model was formulated as a poroelastic system comprising three sets of equations: (1) Darcy's law governing the fluid flow in the gap; (2) the mass balance equation and fluid pressure continuity regulating the fluid exchange between the contact gap and cartilage tissue; (3) the momentum balance equation stating the stress equilibrium state in the contact gap, in which an exponential constitutive equation is assumed for the asperity local deformation under effective contact stresses.

\subsubsection{Contact gap flow and gap permeability}

Owing to the large length scale difference between the contact gap $(5-10 \mu \mathrm{m})$ and cartilage thickness $(2-4 \mathrm{~mm})$, the fluid flow in the contact gap was approximated as a one-dimensional problem and modeled based on Darcy's law as follows:

$$
v_{\mathrm{d}}^{\mathrm{g}}=-K_{\mathrm{g}} \frac{\partial p_{\mathrm{g}}}{\partial r}
$$

where $v_{\mathrm{d}}^{\mathrm{g}}$ is the Darcy velocity of the gap flow, $p_{\mathrm{g}}$ is the gap fluid pressure, and $K_{\mathrm{g}}$ is the gap permeability. In Darcy's law, permeability can be regarded as the ratio of the intrinsic permeability of the pore network (in this case, the gap space) to the fluid viscosity. The intrinsic permeability is governed by the pore size, shape, and connectivity. The gap permeability for $h>1 \mu \mathrm{m}$ can be numerically computed by upscaling a microscale gap flow model through a homogenization process $[37,38]$. The methodology and simulation process are outlined in Fig. 4.

To accurately simulate the gap flow, two cartilage surface roughness profiles measured from the bovine lateral femur (LF) and medial tibia (MT) using a Dektak stylus profilometer from previous studies $[37,39]$ were adopted in this study. The samples $(n=$ 3 for each condyle) were stored at $-20{ }^{\circ} \mathrm{C}$; prior to testing, they were thawed in phosphate-buffered saline (PBS) to room temperature. During the measurement, the moisture of the samples was maintained throughout the imaging process. The samples were scanned at a speed of $100 \mu \mathrm{m} / \mathrm{s}$ with a resolution of $0.33 \mu \mathrm{m} / \mathrm{pt}$ on the $y$-axis and 200 scans were conducted on the $x$-axis, and the resolution of the $z$-axis was $8 \mathrm{~nm}$ $[37,39]$. Both roughness profiles were for an area measuring $1,000 \mu \mathrm{m} \times 1,000 \mu \mathrm{m}$. These profiles were imported to a CFD model as representative elementary volumes for the microscale gap flow [37]. An isothermal, laminar, and incompressible fluid flow with constant viscosity in the contact gap was assumed for the microscale CFD model, which was modeled based on the Navier-Stokes equations without the body force.

$$
\left\{\begin{array}{l}
\nabla \cdot \boldsymbol{u}=0 \\
\rho_{\mathrm{g}} \frac{\partial \boldsymbol{u}}{\partial t}+\rho_{\mathrm{g}}(\boldsymbol{u} \cdot \nabla) \boldsymbol{u}=\nabla \cdot\left[-p_{\mathrm{g}} \boldsymbol{I}+\eta_{\mathrm{g}}\left(\nabla \boldsymbol{u}+(\nabla \boldsymbol{u})^{T}\right]\right.
\end{array}\right.
$$

where $\rho_{\mathrm{g}}=1,225 \mathrm{~kg} / \mathrm{m}^{3}$, which is the density of synovial fluid; $u$ is the fluid velocity vector; $\eta_{\mathrm{g}}=$ $0.01 \mathrm{~Pa} \cdot \mathrm{s}$, which is the viscosity of synovial fluid in the gap.

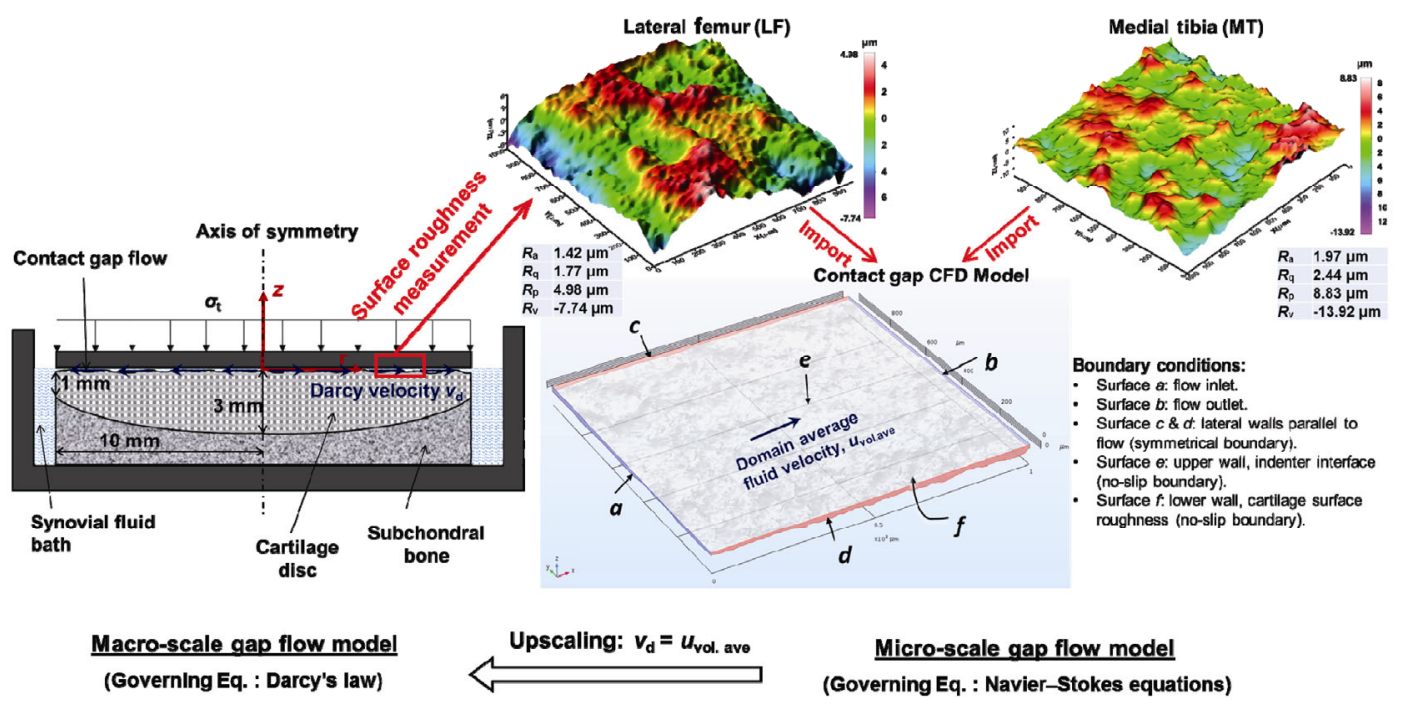

Fig. 4 Determination of gap permeability in roughness dominant layer by model upscaling. 
Upscaling from micro- to macro-level gap flow was achieved through the volume-averaged velocity $u_{\text {vol.ave }}$ of the CFD mode [38], and the gap permeability is expressed as

$$
\begin{aligned}
& u_{\text {vol.ave }}=\frac{1}{V} \int_{\mathrm{REV}} u_{i} \mathrm{~d} V_{i}=v_{\mathrm{d}}^{\mathrm{g}} \\
& K_{\mathrm{g}}=v_{\mathrm{d}}^{\mathrm{g}} \frac{\Delta r}{\Delta p_{\mathrm{g}}}=u_{\text {vol.ave }} \frac{\Delta r}{\Delta p_{\mathrm{g}}}(\text { for } h \geq 1 \mu \mathrm{m})
\end{aligned}
$$

As the permeability was dependent on the gap size, separated CFD models were developed for gap sizes larger than $1 \mu \mathrm{m}$, and the results were approximated using a trendline.

Quantitative information regarding the GAG concentration within PBB is limited. However, the GAG concentration on the cartilage tissue surface has been determined previously via magnetic resonance imaging (MRI) to be approximately $25 \mathrm{mg} / \mathrm{mL}$ [34]. The gap permeability at $h=1 \mu \mathrm{m}$ computed by the CFD method above was on the order of $10^{-11}-10^{-10}$ $\mathrm{m}^{2} /(\mathrm{Pa} \cdot \mathrm{s})$. If we assume that the gap permeability is continuous over $h=1 \mu \mathrm{m}$, then by extrapolating the experimental curve of the hydraulic conductivity of the proteoglycan solution [25], the magnitude of permeability estimated by the CFD method is approximately equivalent to an average GAG concentration of $0.65 \mathrm{mg} / \mathrm{mL}$ in the contact gap. This concentration is extremely small, i.e., less than the minimum value of the typical concentration range tested in the experiment [25], and its effect on the gap permeability is minimal. Therefore, it is reasonable to disregard the effect of the GAG concentration on the gap permeability at $h=1 \mu \mathrm{m}$. Furthermore, at $h=0$, it is reasonable to assume that the GAG concentration in the contact gap approaches the GAG concentration on the cartilage tissue surface $\left(c_{\mathrm{agg}}^{\mathrm{c}}\right.$, set as $25 \mathrm{mg} / \mathrm{mL}$ in this study [34]). For gap size between 0 and $1 \mu \mathrm{m}$, similar to the GAG profile in the cartilage tissue [34], it is assumed that the "effective GAG concentration" in the contact gap varies inversely with the gap size; therefore, its depth-dependent concentration profile during deformation can be simplified to

$$
c_{\text {agg }}^{\mathrm{g}}=\left.c_{\mathrm{agg}}^{\mathrm{c}}\right|_{z=0} \cdot\left(t_{\mathrm{PBB}}-h\right) / t_{\mathrm{PBB}}
$$

where $t_{\mathrm{PBB}}=1 \mu \mathrm{m}$ is the thickness of PBB.
According to previous experimental findings [25], the gap permeability in PBB $(h<1 \mu \mathrm{m})$ was assumed to decrease exponentially with the effective GAG concentration, approximated as follows:

$$
K_{\mathrm{g}}=\left.K_{\mathrm{g}}\right|_{h=1 \mu \mathrm{m}} \cdot \mathrm{e}^{a \cdot c_{\mathrm{ggg}}^{\mathrm{g} g}}(\text { for } h<1 \mu \mathrm{m})
$$

where $a=\left[\ln \left(\left.K_{\mathrm{c}}\right|_{z=0 \mathrm{~mm}} /\left.K_{\mathrm{g}}\right|_{h=1 \mu \mathrm{m})}\right) / t_{\mathrm{PBB}}\right.$ and is an empirical constant. By substituting Eq. (12) into Eq. (13), the variation of the gap permeability in PBB during deformation can be defined, as shown in Fig. 5. It exhibits a linear variation on a semi-log plot between the two bounding permeabilities.

\subsubsection{Fluid exchange}

Two flow paths exist for the fluid in the contact gap. One path is along with the lateral gap space and is modeled by Darcy's law, as shown in Eq. (9). The
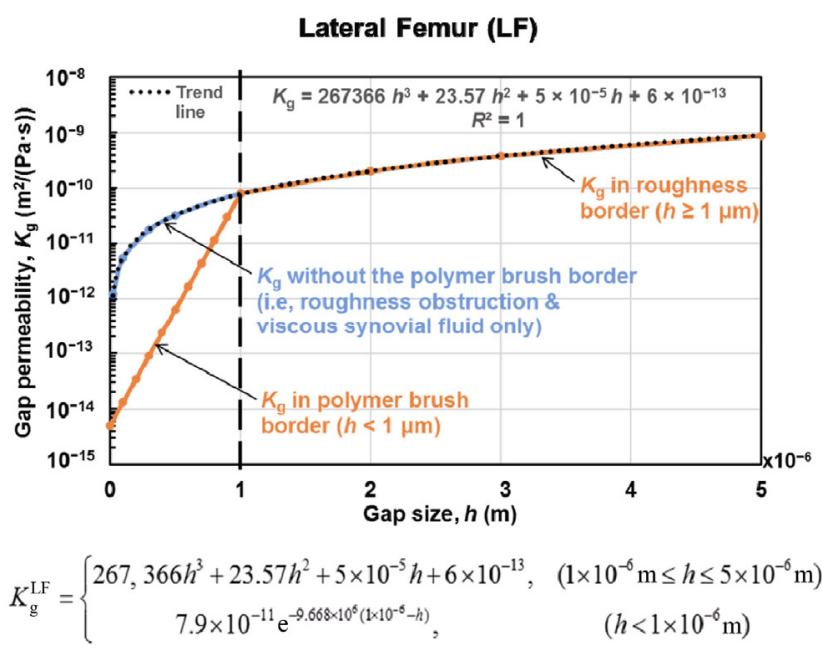

\section{Medial Tibia (MT)}

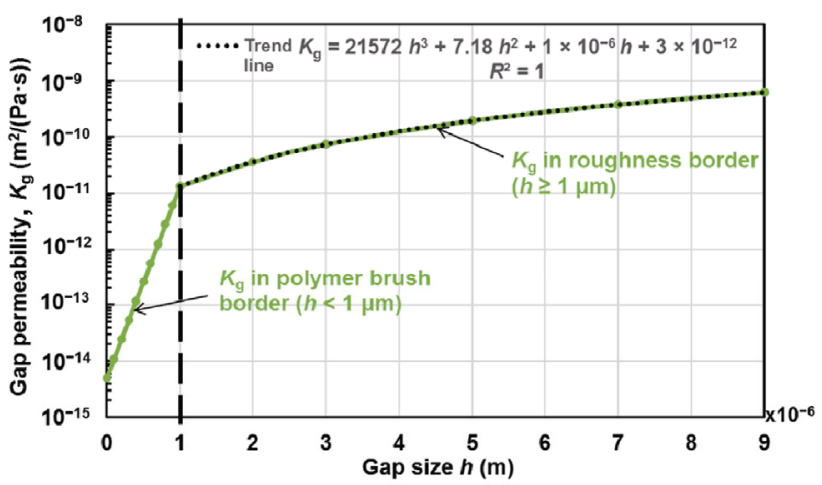

$$
K_{\mathrm{g}}^{\mathrm{MT}}=\left\{\begin{array}{cc}
21572 h^{3}+7.18 h^{2}+1 \times 10^{-6} h+3 \times 10^{-12}, & \left(1 \times 10^{-6} \mathrm{~m} \leq h \leq 9 \times 10^{-6} \mathrm{~m}\right) \\
1.35 \times 10^{-11} \mathrm{e}^{-7.9 \times 10^{8}\left(1 \times 10^{-5}-h\right)}, & \left(h<1 \times 10^{-6} \mathrm{~m}\right)
\end{array}\right.
$$

Fig. 5 Gap permeability of lateral femur (LF) and medial tibia (MT) surface roughness. 
other flow path is into/out of the cartilage tissue, resulting in the fluid exchange between the interstitial fluid in the cartilage tissue and the fluid in the gap space. The fluid exchange that occurs as the gap closes can be modeled by employing Darcy's law in the mass balance equation for incompressible fluid as follows:

$$
\frac{\partial \varepsilon_{\mathrm{v}}^{\mathrm{g}}}{\partial t}+\nabla \cdot v_{\mathrm{d}}^{\mathrm{g}}=s
$$

where $\varepsilon_{\mathrm{v}}^{\mathrm{g}}$ is the volumetric strain of the contact gap and $s$ is the fluid exchange between the gap and tissue per unit volume per unit time.

An integration of $s$ over the gap space reveals the fluid flow rate into or out of the contact gap space; it is associated with the vertical component (z-axis) of the Darcy velocity of cartilage tissues at the contact surface, which is detailed in Section 2.2.1. It is noteworthy that $s$ may be into or out of the tissue; however, our previous study showed that $s$ is a "source" term (i.e., $s>0$ ), meaning that the interstitial fluid in the cartilage tissue "weeps" (or exudes) into the gap space from the cartilage [20]. However, the fluid exudate from the cartilage had much lower viscosity compared with the synovial fluid, which exhibited an effect that increased the gap permeability, thereby reducing the duration of elevated gap fluid pressure and accelerating gap closure. Hence, in this study, we investigated a model that considered PBB.

\subsubsection{Constitutive relationship for gap space}

A constitutive equation is required to describe asperity compression during the closure of the gap space. First, the effective stress principle must be defined based on porous media theory. The principle of effective stress states that the total stress is supported by the solid phase stress $\left(\sigma_{\mathrm{c}}\right)$ and fluid phase stress $\left(p_{\mathrm{g}}\right)$ within the contact gap, as follows:

$$
\sigma_{\mathrm{t}}=\sigma_{\mathrm{c}}-p_{\mathrm{g}}
$$

where $\sigma_{\mathrm{c}}$ is the effective asperity contact stress. It is noteworthy that Eq. (15) represents the vertical stress equilibrium state along the $z$-axis.

The volumetric strain of the gap is primarily related to the reduction in gap size $h$ under the asperity contact stress $\sigma_{\mathrm{c}}$. Because the stress-strain relationship of the cartilage tissue is exponential, as per experimental observations [40], it is reasonable to assume an exponential constitutive equation for the asperity deformation (i.e., gap closure) under contact stress $\sigma_{\mathrm{c}}$, as follows:

$$
h=h_{0} \mathrm{e}^{\sigma_{\mathrm{c}} / \beta}=h_{0} \mathrm{e}^{\left(\sigma_{\mathrm{t}}+p_{\mathrm{g}}\right) / \beta}
$$

where $h_{0}$ is the initial (i.e., the first asperity contact) gap size, which is equal to the peak roughness height in our case, i.e., $h_{0}=R_{\mathrm{p}}$. As shown in Fig. 4 , the values of $h_{0}$ are approximately 5 and $9 \mu \mathrm{m}$ for the LF and MT surface, respectively. $\beta$ is the stiffness of the cartilage asperity, which was set as $1 / 5$ of the cartilage tissue aggregate modulus $H_{-\mathrm{A}}$, as reported by Graindorge et al. [22]. The cartilage tissue aggregate modulus $H_{-\mathrm{A}}$ is detailed in Section 2.2.1.

\subsubsection{Boundary and initial conditions}

To couple the governing equations of the cartilage tissue and contact gap, a few boundary conditions [41] must be employed at the contact interface $(z=$ $0 \mathrm{~mm}$ ), as follows:

$$
\begin{aligned}
& \text { At } z=0 \mathrm{~mm}, \quad \boldsymbol{v}_{\mathrm{d}}^{\mathrm{c}} \cdot \boldsymbol{n}=\boldsymbol{v}_{\mathrm{d}}^{\mathrm{g}} \cdot \boldsymbol{n} \\
& \text { At } z=0 \mathrm{~mm}, \quad p_{\mathrm{c}}=p_{\mathrm{g}}
\end{aligned}
$$

It is noteworthy that the unit normal to the contact interface is denoted by $\boldsymbol{n}$. Equations (17a) and (17b) ensure the continuity of the fluid flux (i.e., the Darcy velocity) normal to the cartilage-gap boundary and the fluid pressure across the cartilage-gap boundary, respectively. In addition, the total surface traction $\sigma_{\mathrm{t}}$ normal to the contact gap and cartilage tissue is continuous.

For both the cartilage tissue and contact gap, the fluid pressure at the perimeter edge is equal to the reference ambient fluid pressure, typically set as zero [42].

$$
\begin{aligned}
& \text { At } r=10 \mathrm{~mm}, \quad p_{\mathrm{c}}=0 \\
& \text { At } r=10 \mathrm{~mm}, \quad z=0 \mathrm{~mm}, \quad p_{\mathrm{g}}=0
\end{aligned}
$$

The osteochondral junction was assumed to be a fixed and impermeable surface; hence, these boundary conditions were applied in the model [33].

Furthermore, an initial condition was required for the contact gap model. This is expressed by the stress equilibrium state shown in Eq. (15). The analysis starts when a contact is established with the highest asperity. At this instant, the contact stress 
$\sigma_{\mathrm{c}}=0$; therefore, the total applied load is assumed to be solely resisted by the fluid pressure in the gap space (i.e., $\sigma_{\mathrm{t}}=-p_{\mathrm{g}}$ ), and the gap size is at its maximum extent (i.e., $h=h_{0}$ ). Mathematically,

$$
\text { At } \quad t=0, \quad p_{\mathrm{g}}=-\sigma_{\mathrm{t}}, \quad h=h_{0}
$$

When the gap begins to close, the surface asperities are deformed and the gap fluid is squeezed out; consequently, $\sigma_{\mathrm{c}}$ increases while $p_{\mathrm{g}}$ decreases.

\subsection{Computational modelling}

Computational models in both the microscale (CFD model) and macroscale (cartilage contact model) were conducted using the commercial software package COMSOL Multiphysics (version 5.3, COMSOL, Inc.).

A typical microscale CFD model and its boundary conditions are shown in Fig. 4. For an approximation, fluid exchange and fluid-structure interaction were not considered in the microscale model. The input pressure was $100 \mathrm{kPa}$, which resulted in the same initial fluid pressure gradient as that in the macroscale model. The gap closure was modeled by slicing up the asperities by the upper wall at different gap sizes, as the Poisson's ratio of the cartilage extracellular matrix was approximately zero [35]. A mesh sensitivity test was performed in advance with "coarse", "normal" and "fine" mesh options in COMSOL [43]. The results showed that the differences in $u_{\text {volave }}$ were less than $1 \%$. To balance simulation time and accuracy, the "normal" mesh was adopted; 296,147 free tetrahedral elements were used, including two boundary layers (131,873 elements) at the upper and lower walls and 1,738 corner elements. The parallel sparse direct solver was selected, and the relative tolerance was set to 0.001 .

The geometry and dimensions of the macroscale integrated contact model are shown in Fig. 3. The dimensions of the model were obtained from MRI images [44]. The cartilage thickness remained relatively constant around the center ( $3 \mathrm{~mm}$ thick) and was then gradually decreased toward the edge of the tibial plateau ( $1 \mathrm{~mm}$ thick), from a distance of $2 / 3$ the cartilage disc radius $(10 \mathrm{~mm})$. The model was meshed using 1896 free tetrahedral elements, in which the average element size was $0.1 \mathrm{~mm}$. The numerical analysis was halted after $1 \mathrm{~h}$ of simulation for a 1-MPa indentation. The model was solved by the time-dependent implicit solver using the backward differentiation formula time stepping method. The relative tolerance was set to $10^{-3}$.

\section{Results and discussion}

In this section, the effects of PBB on cartilage lubrication are first analyzed. Subsequently, the effects of the roughness vertical height, synovial fluid viscosity, and PBB thickness on cartilage lubrication are discussed.

\subsection{Effects of PBB}

To investigate the effects of PBB on cartilage lubrication, we considered models that either included or disregarded the presence of a PBB. Both models were used to simulate an LF surface as an example surface. The gap permeability curves are shown in Fig. 5 . For gap sizes of less than $1 \mu \mathrm{m}$, it was observed that the gap permeability for the model without PBB was decreased gradually as the gap began closing. This occurred because only the gap flow resistance arising from roughness obstructions and the viscous synovial fluid were considered. Meanwhile, the gap permeability with $\mathrm{PBB}$ decreased more rapidly with the closing gap size, compared with the case without PBB. It is noteworthy that for the part where $h>1 \mu \mathrm{m}$, the permeability curves were independent of the presence or absence of PBB.

A few metrics were used to understand the interaction between the cartilage tissue and the contact gap, as well as their synergistic effects on cartilage lubrication. Specifically, the metrics were the gap fluid load support fraction, cartilage interstitial fluid pressure, and cartilage vertical strain along the $z$-axis.

The fluid pressure distribution in the contact gap during the first $30 \mathrm{~min}$ of contact is shown in Fig. 6(a), in which both cases with (solid lines) and without PBB (dashed lines) are plotted together for comparison. As shown, the gap fluid pressure decayed gradually toward the contact center, and it declined more rapidly without PBB. For example, for a 10-min contact, the gap fluid pressure without $\mathrm{PBB}$ was decreased to $1 / 10$ of the applied load, whereas with $\mathrm{PBB}$, the gap fluid pressure was approximately five-fold greater, 
particularly at the area near the contact center $(r<$ $5 \mathrm{~mm}$ ); nevertheless, the gap fluid pressure can still be maintained at approximately $65 \%$ of the applied load. It is more meaningful to analyze the gap fluid load support $W^{\mathrm{f}}$, which is obtained by integrating the gap fluid pressure over the cartilage surface. It is a key parameter in evaluating cartilage lubrication performance, equivalent to the monitoring of hydrodynamic lubrication. The coefficient of friction is directly proportional to the normal load supported by the solid phase at asperity contacts $W^{s}$ [45], which is obtained by subtracting the fluid load support $W^{\mathrm{f}}$ from the total applied load $W^{\text {tot }}$ (i.e., $\left.W^{\mathrm{s}}=W^{\text {tot }}-W^{\mathrm{f}}\right)$. The gap fluid load support fraction $\left(W^{\mathrm{f}} / W^{\text {tot }}\right)$ is shown in Fig. 6(a). In both cases, the gap fluid support fraction decreased with loading time, but the support decreased the most rapidly without PBB. For example, at 1,200 s, the gap fluid load support without PBB was almost exhausted ( $2 \%$ of the total load). By contrast, the gap fluid load support fraction still remained at approximately $40 \%$ of the total load with PBB (26

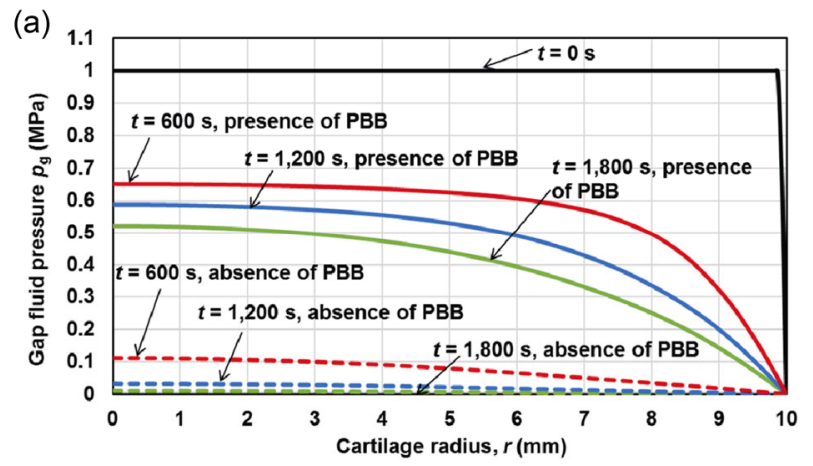

Spatial distribution of gap fluid pressure
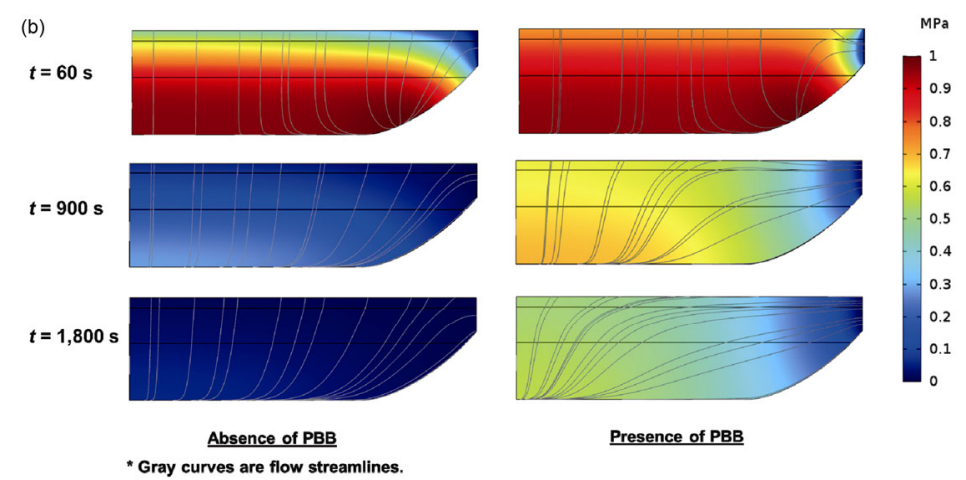

higher than that without PBB). The gap fluid load support fraction decreased gradually and was less than $20 \%$ after a 1 -h indention. The results above indicate that at 1,200 s when considering PBB, the asperity solid-to-solid load support was approximately $40 \%$ less than that of the model without PBB, implying a $40 \%$ smaller coefficient of friction.

To further investigate the effect of PBB, the contour plots of interstitial fluid pressure (i.e., the fluid pressure within the cartilage) are shown in Fig. 6(b). Without $\mathrm{PBB}$, the interstitial fluid pressure decreased rapidly. For example, the fluid pressure near the center of the tissue $(r=0, z=-1.35 \mathrm{~mm})$ decreased to $0.04 \mathrm{MPa}$ after a 30-min indentation, whereas in the same condition, the fluid pressure with PBB was more than 10 times greater at 0.52 $\mathrm{MPa}$. The fluid pressurization in the gap was due to the interstitial cartilage fluid exuding into the contact interface, as clearly indicated by the streamlines intersecting the cartilage surface. During the early contact stage (at $t=60 \mathrm{~s}$ ), with and without PBB, the interstitial cartilage fluid wept into the contact

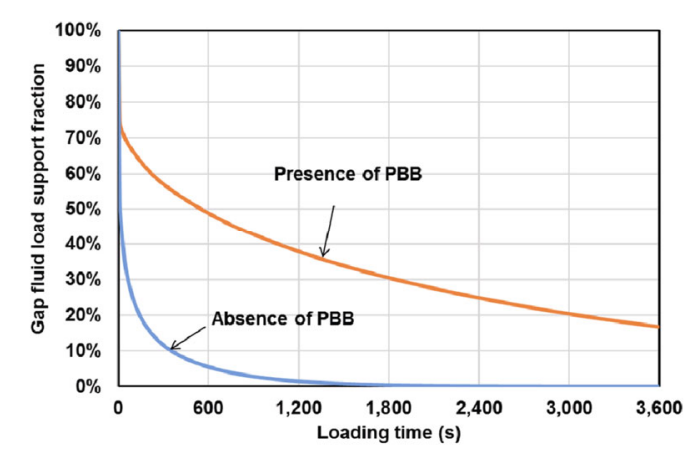

Temporal changes of gap fluid load support

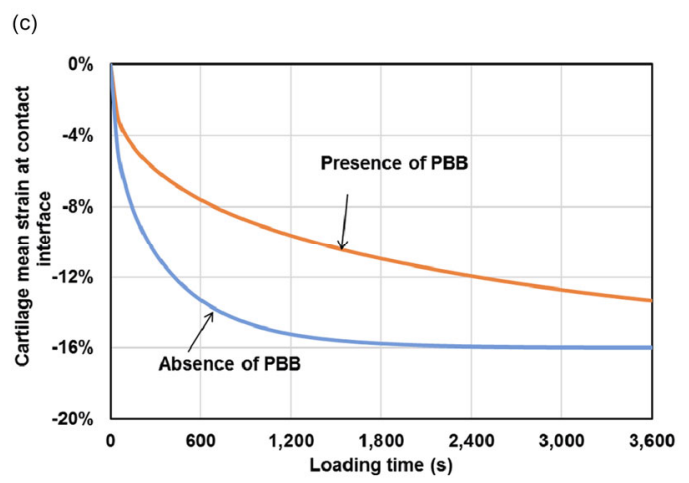

Fig. 6 Effect of presence and absence of polymer brush border (PBB) on factors affecting cartilage lubrication: (a) gap fluid pressure and gap fluid load support fraction; (b) contour plots of the interstitial fluid pressure of cartilage tissue at three time points; (c) mean vertical strain over contact interface. 
gap space. Without PBB, this weeping process was continuous and occurred over the entire contact surface. However, owing to the fluid flow resistance provided by the surface polymers in the gap space, the weeping process decelerated significantly and occurred primarily in the region close to the contact center, as indicated by the streamlines at $t=900$ and $1,800 \mathrm{~s}$. Furthermore, more fluid had to be exuded from the "side outlet", thereby involving much longer drainage paths. Therefore, the rate of interstitial fluid pressure drop was decreased significantly by PBB. The slowdown of the weeping process can be further quantified by comparing the fluid exudation volume of the two cases after a 1-h indentation, as shown in Table 1. Without PBB, the fluid exudation volume to the contact interface after a 1-h indentation was $0.117 \mathrm{~mL}(88 \%$ of its total exudation volume), which was almost seven times that of its counterpart with PBB $(0.017 \mathrm{~mL})$.

The results suggest the critical role of $\mathrm{PBB}$ in prolonging the load support by maintaining the interstitial fluid pressure in the tissue, extending the weeping lubrication period, and extending the duration of the hydrodynamic mode of lubrication. Without PBB, the cartilage interstitial fluid can be rapidly squeezed out under high contact loading, thereby increasing solid-to-solid contracts at the interface as well as increasing the associated frictional wear. In other words, the fluid permeability in the contact gap with PBB will be lowered, rendering it more difficult for the fluid to exude from the articular cartilage and to be squeezed out of the contact gap space. The surface polymers fixed to the cartilage surface cannot be squeezed out of the gap space, unlike other components of the amorphous layer on the cartilage surface. Therefore, weeping exudation from the articular cartilage in the presence of $\mathrm{PBB}$ serves to extend the duration of the hydrodynamic lubrication mode, thereby reducing friction between contacting cartilage surfaces.

Table 1 Summary of fluid exudation volume after 1-h indentation (LF surface).

\begin{tabular}{ccc}
\hline Fluid exudation $(\mathrm{mL})$ & Absence of PBB & Presence of PBB \\
\hline Top & 0.117 & 0.017 \\
Side & 0.016 & 0.095 \\
Total & 0.133 & 0.112 \\
\hline
\end{tabular}

To further investigate the role of $\mathrm{PBB}$, we next consider its effect on the cartilage biomechanical performance. A comparison of the average cartilage vertical strains over the contact interface of the two cases is shown in Fig. 6(c). When PBB was included in the model, the average vertical strain after $30 \mathrm{~min}$ of loading was $11 \%$ (compared with $16 \%$ without $\mathrm{PBB})$, a prediction that matched reasonably well with in vivo measurements under similar loading conditions. Halonen et al. [46] utilized computed tomography arthrography to measure the cartilage strain. The test subject was standing on one leg supporting approximately half of the bodyweight with the aid of harnesses ( $386 \mathrm{~N})$. The total knee joint reaction force was reported to be approximately the full body weight (107\%) [46]. If we assume that the load is approximately equally shared by both joint condyles, then the total force on one condyle is approximately half the body weight (386 N), which is comparable to the loading condition of our modeling in this study $(314 \mathrm{~N})$. The strains after 30 min of contact were obtained by comparing computed tomography (CT) images, and they were $12 \%$ and $10 \%$ for the lateral and medial tibia, respectively [46]. This comparison verifies the model predictions performed in this study for the model with PBB. This suggests that it is essential to include PBB in cartilage contact modeling for an accurate simulation.

After $1 \mathrm{~h}$ of indentation, the cartilage strain in the model without PBB reached an equilibrium state at $16 \%$ strain, which was approximately $19 \%$ higher than the strain with PBB (at 13\%). This was due to the additional fluid exudation that occurred at the contact interface in the model without PBB. As shown in Table 1, the total fluid exudation without PBB $(0.133 \mathrm{~mL})$ was exactly $19 \%$ higher than that of its counterpart model with PBB $(0.112 \mathrm{~mL})$.

In summary, the study of the two models with and without PBB demonstrates that PBB can provide significant additional resistance to the exudate fluid flow along the contact gap, offering two benefits. First, the flow resistance in the gap space limits the rate of fluid exudation to the contact gap, thereby maintaining the interstitial fluid pressure inside the cartilage tissue and reducing tissue strain. Second, the fluid load support in the contact gap can be 
maintained for a much longer period that is comparable to the consolidation time of the cartilage, as the consolidation process results in exudate flowing into the contact gap space. This behavior increases the fraction of hydrodynamic lubrication at the contact interface, and hence reduces the contact friction and surface wear.

\subsection{Effect of synovial fluid viscosity}

The viscosity of the healthy synovial fluid can vary by several orders of magnitude owing to its shear rate dependence. Using the MT surface (Fig. 4) and its gap permeability (Fig. 5), a parametric study was performed to assess the effect of the synovial fluid viscosity on cartilage lubrication. Three constant viscosity values for synovial fluid with 10-fold differences (i.e., 1, 0.1, and 0.01 Pa·s) were compared, as well as that of water (0.001 Pa·s), whereas all the other model parameters were fixed. The results are shown in Fig. 7(a).

(a)

(b)
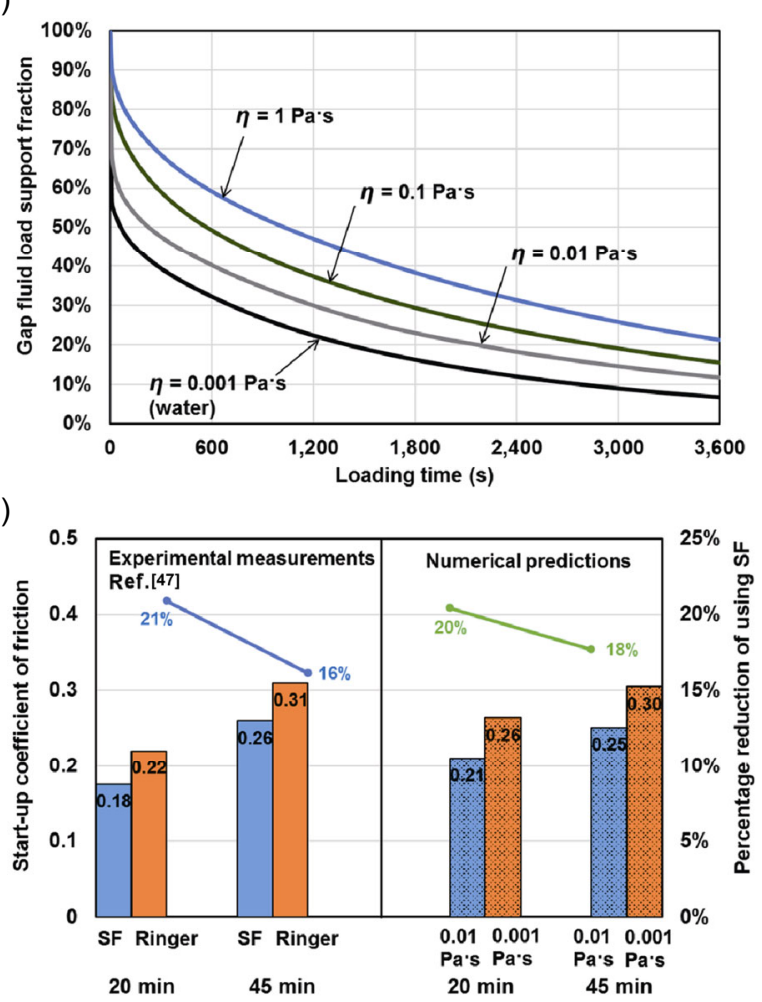

Fig. 7 Effect of the viscosity of synovial fluid on cartilage lubrication: (a) Comparison of normalized gap fluid load support among various viscosities; (b) comparison of coefficient of friction between model predictions and experimental measurements [47] (SF denotes "synovial fluid", Ringer denotes "Ringer's solution").
The gap fluid support fraction decreased as the viscosity decreased. For example, at $t=1,800 \mathrm{~s}$, if we consider a gap fluid support of $1 \mathrm{~Pa} \cdot \mathrm{s}$ as the reference point, every 10 -fold decrease in the viscosity magnitude (to $0.1,0.01$ and $0.001 \mathrm{~Pa} \cdot \mathrm{s}$ ) will result in a reduction in the gap fluid support by $23 \%, 40 \%$, and $58 \%$, respectively. In other words, for a viscosity reduction of 1,000 times (from 1 to $0.001 \mathrm{~Pa} \cdot \mathrm{s}$ ), the gap fluid load support declines by $58 \%$.

This viscosity result suggests that synovial fluid can enhance the fluid support fraction in the gap space, thereby reducing the friction coefficient. Next, we compare experimental findings with our model predictions. Forster and Fisher [47] measured the initial friction coefficient of cartilage on metal contact, in which Ringer's solution or synovial fluid was used as the lubricant. The most significant differences in friction coefficient that they recorded were at loading times of 20 and $45 \mathrm{~min}$, where the coefficient of frictions using synovial fluid ( $\mu_{0}=0.18$ and 0.26 ) were only $21 \%$ and $16 \%$ less than those using Ringer's solution ( $\mu_{0}=0.22$ and 0.31 , respectively). The experimental results matched reasonably well with our computational predictions, particularly in terms of the percentage of difference plotted in Fig. 7(b).

It can be reasonably assumed that the viscosity cases of 0.01 and $0.001 \mathrm{~Pa} \cdot \mathrm{s}$ in Fig. 7(a) correspond to the synovial fluid and Ringer's solution case of Forster and Fisher [47]. By regarding the contact gap as a porous medium, the effective coefficient of friction $\mu_{\text {eff }}$ can be computed based on biphasic lubrication theory as follows [41]:

$$
\mu_{\text {eff }}=\frac{F}{W^{\text {tot }}}=\mu_{\text {eq }} \frac{W^{\mathrm{s}}}{W^{\text {tot }}}=\mu_{\text {eq }} \frac{W^{\text {tot }}-W^{\mathrm{f}}}{W^{\text {tot }}}
$$

where $\mu_{\mathrm{eq}}$ is the coefficient of friction in the equilibrium state. As shown in Fig. 7(b), by assuming $\mu_{\mathrm{eq}}=0.3$ [45], the predicted coefficients of friction of $\eta=0.01 \mathrm{~Pa} \cdot \mathrm{s}$ at 20 and $45 \mathrm{~min}$ (i.e., 0.21 and 0.25 ) were $20 \%$ and $18 \%$ less than those of $\eta=0.001 \mathrm{~Pa} \cdot \mathrm{s}$ at 20 and $45 \mathrm{~min}$ (i.e., 0.26 and 0.30 ), respectively. The percentage of differences was similar to the experimental measurements [47]. This study provides a reasonable and possible theoretical explanation for the experimental observations. However, it is noteworthy that the different amounts of lubricin in the experiments may affect the friction measurements 
(particularly at $45 \mathrm{~min}$ when the cartilage was near equilibrium [47], i.e., mainly in the boundary lubrication regime), and the effect of lubricin on cartilage lubrication is beyond the scope of this study. Nevertheless, as suggested by Forster and Fisher [47], the friction coefficient of articular cartilage is primarily affected by fluid load support.

\subsection{Effect of PBB thickness}

The effect of PBB thickness on cartilage lubrication is considered in this section. Experimental studies have shown that PBB thickness can range from $200 \mathrm{~nm}$ to a few microns [13]. In this study, three thickness values ( $200 \mathrm{~nm}, 500 \mathrm{~nm}$, and $1 \mu \mathrm{m})$ were investigated using the LF surface, and the viscosity was maintained at $0.01 \mathrm{~Pa} \cdot \mathrm{s}$.

The results of PBB thickness are shown in Fig. 8(a). In general, the cartilage lubrication varied inversely with the PBB thickness. Considering $t=1,800 \mathrm{~s}$ as

(a)

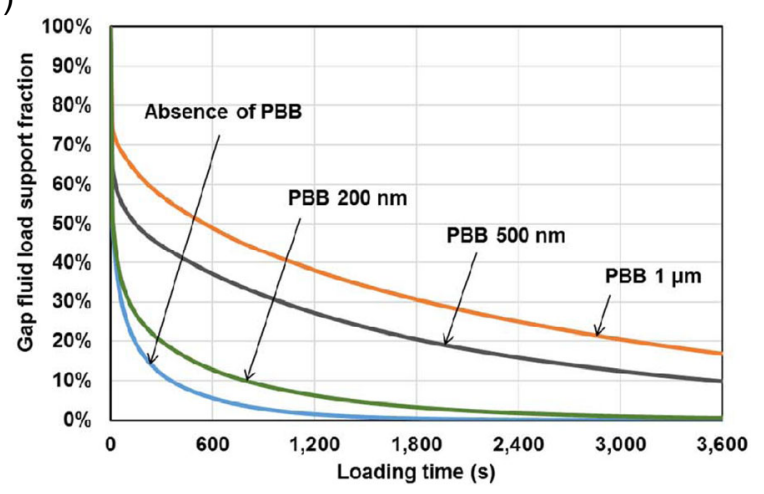

(b)

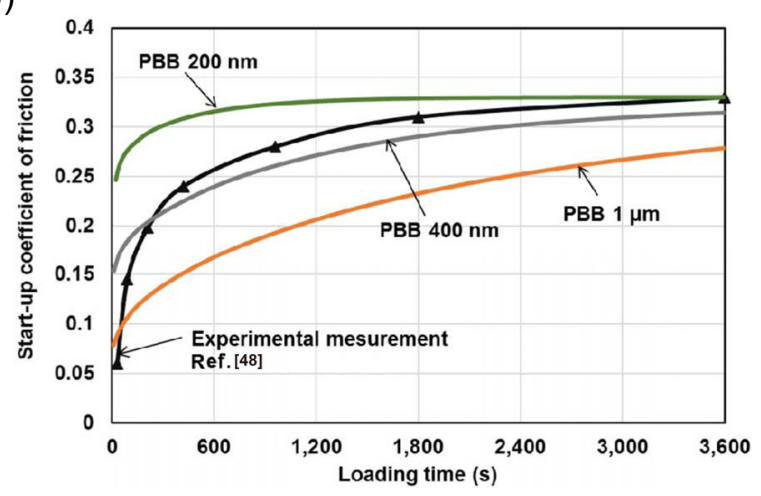

Fig. 8 Effect of thickness of polymer brush border on cartilage lubrication: (a) Comparison of normalized gap fluid load support among various thicknesses (viscosity maintained at $0.01 \mathrm{~Pa} \cdot \mathrm{s}$ ); (b) comparison of coefficient of friction between model predictions (viscosity maintained at $0.001 \mathrm{~Pa} \cdot \mathrm{s}$ ) and experimental measurements [48]. an example, by reducing the PBB thickness by $50 \%$ (i.e., from $1 \mu \mathrm{m}$ to $500 \mathrm{~nm}$ ), the gap fluid load support decreased by $33 \%$, whereas another $60 \%$ reduction in thickness (i.e., from 500 to $200 \mathrm{~nm}$ ) resulted in a further $84 \%$ decrease in the gap fluid load support.

Figure 8 (b) shows the time-dependent coefficients of friction as the PBB thickness was varied between $200 \mathrm{~nm}$ and $1 \mu \mathrm{m}$, and water (0.001 Pa.s) was used as the lubricant. The predicted time-dependent variation of the coefficient of friction for the $\mathrm{PBB}$ thickness of $400 \mathrm{~nm}$ (using Eq. (21), in which $\mu_{\mathrm{eq}}$ is 0.33 , as per the experimental measurements) can yield a reasonably close approximation to (particularly after $300 \mathrm{~s}$ ) the experimental measurement reported by Accardi et al. [48] (the test was performed in PBS at a contact pressure of 1.2-1.8 MPa).

\section{Limitations}

This study has some limitations. First, to simplify the model complexity, the shear rate dependent viscosity of synovial fluid was not considered in the model. Our previous study showed that with reductions in gap pressure gradients with gap closure, the viscosity may increase [37]. The increase in viscosity might decrease the gap permeability and hence further prolong the gap fluid load support. Second, the interaction deformation between the asperity and the bulk tissue was not considered in the simulation. In future studies, a relationship between the local asperity deformation and tissue bulk consolidation must be established through experimental observations (e.g., measuring the surface roughness at different cartilage strains). Third, the model can be improved by the availability of experimental data regarding GAG content or the fixed charge density in PBB. This can be achieved using high-strength MRI scanners with sufficiently high resolution or the tracer cation method using ${ }^{22} \mathrm{Na}$ [49]. Furthermore, it may be more beneficial to directly model the interactions of the surface polymers and solvent molecules in normal joint motions [27].

\section{Conclusions}

In this study, PBB on the cartilage surface was integrated using a coupled contact model. The effect 
of synovial fluid viscosity and the PBB thickness on cartilage lubrication were investigated computationally. The conclusions obtained were as follows:

1) PBB can substantially enhance cartilage lubrication by increasing the gap fluid load support fraction and hence improve the hydrodynamic mode of lubrication. Based on the case study and using the specified parameters, PBB increased the fluid support by 26 times at a $20-\mathrm{min}$ indentation compared with the model without PBB.

2) Weeping (fluid exudation) and hydrodynamic lubrication reduced friction synergistically. The exudation of interstitial fluid from the articular cartilage into the contact gap space prolonged the hydrodynamic mode of lubrication. Owing to the resistance of $\mathrm{PBB}$ to the lateral transport of the exudate along the contact gap space, less fluid was required to sweep into the contact gap while the gap fluid pressure was maintained. Hence, the interstitial fluid pressure within the articular cartilage tissue can be maintained for a longer period, and cartilage deformation can be reduced compared with similar load durations.

3) Synovial fluid improved fluid support in the gap space relative to saline water, as reducing the viscosity magnitude by 1,000 times (from 1 to $0.001 \mathrm{~Pa} \cdot \mathrm{s}$ ) reduced the gap fluid support at $30 \mathrm{~min}$ of indentation by $58 \%$.

4) The PBB thickness significantly affected the cartilage lubrication performance; a $60 \%$ reduction in the PBB thickness (from 500 to $200 \mathrm{~nm}$ ) resulted in an $84 \%$ decrease in the gap fluid load support at $30 \mathrm{~min}$ of indentation.

\section{Acknokledgements}

This study was supported by the Australian Research Council (DP180100915) and the Graduate Research Scholarship by the University of Melbourne.

Open Access This article is licensed under a Creative Commons Attribution 4.0 International License, which permits use, sharing, adaptation, distribution and reproduction in any medium or format, as long as you give appropriate credit to the original author(s) and the source, provide a link to the Creative Commons licence, and indicate if changes were made.
The images or other third party material in this article are included in the article's Creative Commons licence, unless indicated otherwise in a credit line to the material. If material is not included in the article's Creative Commons licence and your intended use is not permitted by statutory regulation or exceeds the permitted use, you will need to obtain permission directly from the copyright holder.

To view a copy of this licence, visit http://creativecommons.org/licenses/by/4.0/.

\section{References}

[1] Kutzner I, Heinlein B, Graichen F, Bender A, Rohlmann A, Halder A, Beier A, Bergmann G. Loading of the knee joint during activities of daily living measured in vivo in five subjects. J Biomech 43(11): 2164-2173 (2010)

[2] Jay G D, Waller K A. The biology of Lubricin: Near frictionless joint motion. Matrix Biol 39: 17-24 (2014)

[3] McCutchen $\mathrm{C}$ W. The frictional properties of animal joints. Wear 5(1): 1-17 (1962)

[4] Walker P S, Dowson D, Longfield M D, Wright V. "Boosted lubrication" in synovial joints by fluid entrapment and enrichment. Ann Rheum Dis 27(6): 512520 (1968)

[5] Klein J. Hydration lubrication. Friction 1(1): 1-23 (2013)

[6] Ikeuchi K. Origin and future of hydration lubrication. Proc Inst Mech Eng Part J: J Eng Tribol 221(3): 301-305 (2007)

[7] Kobayashi S, Yonekubo S, Kurogouchi Y. Cryoscanning electron microscopy of loaded articular cartilage with special reference to the surface amorphous layer. J Anat 188: 311-322 (1996)

[8] Hung C T, Mow V C. Biomechanics of articular cartilage. In Basic biomechanics of the musculoskeletal system. Nordin M, Frankel V H, Eds. New York: Lippincott Williams \& Wilkins, 2001: 60-101.

[9] Smith D W, Gardiner B S, Zhang L H, Grodzinsky A J. Articular cartilage dynamic. Singapore: Springer Singapore, 2019.

[10] Higaki H, Murakami T, Nakanishi Y, Miura H, Mawatari $\mathrm{T}$, Iwamoto Y. The lubricating ability of biomembrane models with dipalmitoyl phosphatidylcholine and $\gamma$ globulin. Proc Inst Mech Eng H 212(5): 337-346 (1998)

[11] Seror J, Merkher Y, Kampf N, Collinson L, Day A J, Maroudas A, Klein J. Articular cartilage proteoglycans as boundary lubricants: Structure and frictional interaction of surface-attached hyaluronan and 
hyaluronan-aggrecan complexes. Biomacromolecules 12(10): 3432-3443 (2011)

[12] Lee Y, Choi J, Hwang N S. Regulation of lubricin for functional cartilage tissue regeneration: A review. Biomater Res 22: 9 (2018)

[13] Katta J, Jin Z M, Ingham E, Fisher J. Biotribology of articular cartilage-A review of the recent advances. Med Eng Phys 30(10): 1349-1363 (2008)

[14] Gu W Y, Lai W M, Mow V C. Transport of fluid and ions through a porous-permeable charged-hydrated tissue, and streaming potential data on normal bovine articular cartilage. J Biomech 26(6): 709-723 (1993)

[15] Murakami T, Nakashima K, Sawae Y, Sakai N, Hosoda N. Roles of adsorbed film and gel layer in hydration lubrication for articular cartilage. Proc Inst Mech Eng Part J: J Eng Tribol 223(3): 287-295 (2009)

[16] Murakami T, Yarimitsu S, Sakai N, Nakashima K, Yamaguchi T, Sawae Y. Importance of adaptive multimode lubrication mechanism in natural synovial joints. Tribol Int 113: 306-315 (2017)

[17] Lee D W, Banquy X, Israelachvili J N. Stick-slip friction and wear of articular joints. PNAS 110(7): E567-E574 (2013)

[18] Graindorge S, Ferrandez W, Ingham E, Jin Z, Twigg P, Fisher J. The role of the surface amorphous layer of articular cartilage in joint lubrication. Proc Inst Mech Eng H 220(5): 597-607 (2006)

[19] Guo H Q, Spilker R L. An augmented Lagrangian finite element formulation for 3D contact of biphasic tissues. Comput Methods Biomech Biomed Eng 17(11): 12061216 (2014)

[20] Liao J J, Smith D W, Miramini S, Gardiner B S, Zhang L H. A coupled contact model of cartilage lubrication in the mixed-mode regime under static compression. Tribol Int 145: 106185 (2020)

[21] Myant C, Cann P. In contact observation of model synovial fluid lubricating mechanisms. Tribol Int 63: 97-104 (2013)

[22] Graindorge S, Ferrandez W, Jin Z M, Ingham E, Grant C, Twigg P, Fisher J. Biphasic surface amorphous layer lubrication of articular cartilage. Med Eng Phys 27(10): 836-844 (2005)

[23] Forster H, Fisher J. The influence of continuous sliding and subsequent surface wear on the friction of articular cartilage. Proc Inst Mech Eng H 213(4): 329-345 (1999)

[24] Jurvelin J S, Müller D J, Wong M, Studer D, Engel A, Hunziker E B. Surface and subsurface morphology of bovine humeral articular cartilage as assessed by atomic force and transmission electron microscopy. J Struct Biol 117(1): 45-54 (1996)

[25] Zamparo O, Comper W D. Hydraulic conductivity of chondroitin sulfate proteoglycan solutions. Arch Biochem Biophys 274(1): 259-269 (1989)

[26] Schurz J, Ribitsch V. Rheology of synovial fluid. Biorheology 24(4): 385-399 (1987)

[27] de Beer S, Kenmoé G D, Müser M H. On the friction and adhesion hysteresis between polymer brushes attached to curved surfaces: Rate and solvation effects. Friction 3(2): 148-160 (2015)

[28] Zhang L H, Gardiner B S, Smith D W, Pivonka P, Grodzinsky A J. A fully coupled poroelastic reactivetransport model of cartilage. Mol Cell Biomech 5(2): 133-153 (2008)

[29] Zhang L H, Miramini S, Smith D W, Gardiner B S, Grodzinsky A J. Time evolution of deformation in a human cartilage under cyclic loading. Ann Biomed Eng 43(5): 1166-1177 (2015)

[30] Barker M K, Seedhom B B. The relationship of the compressive modulus of articular cartilage with its deformation response to cyclic loading: Does cartilage optimize its modulus so as to minimize the strains arising in it due to the prevalent loading regime? Rheumatology 40(3): 274-284 (2001)

[31] Mow V C, Kuei S C, Lai W M, Armstrong C G. Biphasic creep and stress relaxation of articular cartilage in compression: Theory and experiments. J Biomech Eng 102(1): 73-84 (1980)

[32] Zhang L H, Gardiner B S, Smith D W, Pivonka P, Grodzinsky A J. Igf uptake with competitive binding in articular cartilage. J Biol Syst 16(2): 175-195 (2008)

[33] Miramini S, Smith D W, Zhang L H, Gardiner B S. The spatio-temporal mechanical environment of healthy and injured human cartilage during sustained activity and its role in cartilage damage. $J$ Mech Behav Biomed Mater 74: 1-10 (2017)

[34] Wedig M, Bae W, Temple M, Sah R, Gray M. GAG profiles in normal human articular cartilage. In $51^{s t}$ Annal Meeting of the Orthopedic Research Society, Washington D.C., USA, 2005: post No. 0358.

[35] Setton L A, Elliott D M, Mow V C. Altered mechanics of cartilage with osteoarthritis: Human osteoarthritis and an experimental model of joint degeneration. Osteoarthr Cartil 7(1): 2-14 (1999)

[36] Treppo S, Koepp H, Quan E C, Cole A A, Kuettner K E, Grodzinsky A J. Comparison of biomechanical and biochemical properties of cartilage from human knee and ankle pairs. J Orthop Res 18(5): 739-748 (2000)

[37] Liao J J, Smith D W, Miramini S, Thibbotuwawa N, Gardiner B S, Zhang L H. The investigation of fluid flow in cartilage contact gap. $J$ Mech Behav Biomed Mater 95: 153-164 (2019)

[38] Wu Y B, Ferguson S J. The influence of cartilage surface topography on fluid flow in the intra-articular 
gap. Comput Methods Biomech Biomed Eng 20(3): 250-259 (2017)

[39] Liao J J, Miramini S, Liu X C, Zhang L H. Computational study on synovial fluid flow behaviour in cartilage contact gap under osteoarthritic condition. Comput Biol Med 123: 103915 (2020)

[40] Robinson D L, Kersh M E, Walsh N C, Ackland D C, de Steiger R N, Pandy M G. Mechanical properties of normal and osteoarthritic human articular cartilage. $J$ Mech Behav Biomed Mater 61: 96-109 (2016)

[41] Ateshian G A. A theoretical formulation for boundary friction in articular cartilage. $J$ Biomech Eng 119(1): 81-86 (1997)

[42] Pascovici M D, Cicone T. Squeeze-film of unconformal, compliant and layered contacts. Tribol Int 36(11): 791-799 (2003)

[43] COMSOL. CFD Module User's Guide, Version 5.3, 2017.

[44] Goodwin D W, Wadghiri Y Z, Zhu H Q, Vinton C J, Smith E D, Dunn J F. Macroscopic structure of articular cartilage of the tibial plateau: Influence of a characteristic matrix architecture on MRI appearance.

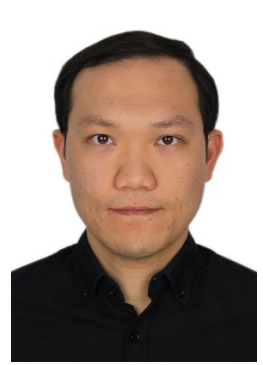

JinJing LIAO. He received his B.Eng. ( $1^{\text {st }}$ Hons) and M.Phil. degrees in civil engineering from the University of Western Australia. He had six years experience in

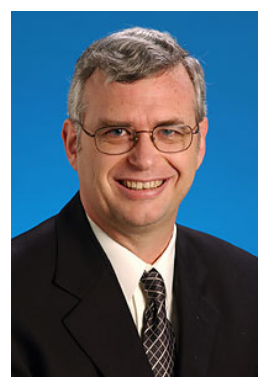

David W. SMITH. He received his Ph.D. degree from the University of Sydney in 1991. He is a professor of biomedical engineering at the University of Western Australia.
Am J Roentgenol 182(2): 311-318 (2004)

[45] Ateshian G A. The role of interstitial fluid pressurization in articular cartilage lubrication. $J$ Biomech 42(9): 1163-1176 (2009)

[46] Halonen K S, Mononen M E, Jurvelin J S, Töyräs J, Salo J, Korhonen R K. Deformation of articular cartilage during static loading of a knee jointExperimental and finite element analysis. $J$ Biomech 47(10): 2467-2474 (2014)

[47] Forster H, Fisher J. The influence of loading time and lubricant on the friction of articular cartilage. Proc Inst Mech Eng H 210(2): 109-119 (1996)

[48] Accardi M A, Dini D, Cann P M. Experimental and numerical investigation of the behaviour of articular cartilage under shear loading-Interstitial fluid pressurisation and lubrication mechanisms. Tribol Int 44(5): 565-578 (2011)

[49] Basser P J, Schneiderman R, Bank R A, Wachtel E, Maroudas A. Mechanical properties of the collagen network in human articular cartilage as measured by osmotic stress technique. Archives of Biochemistry and Biophysics 351(2): 207-219 (1998).

Australian offshore engineering industry as a structural engineer. $\mathrm{He}$ is currently a Ph.D. candidate at the University of Melbourne. His research interests include engineering mechanics, engineering structures, and biotribology.

His research focuses on computational biology, including cellular signal transduction, bone, cartilage, tendon, cell mechanics, physiology of the kidney, problems in developmental biology, etc. 


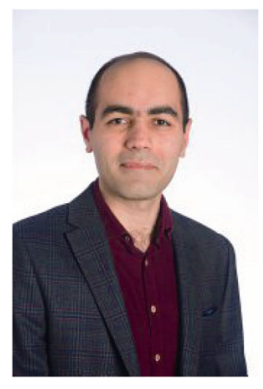

Saeed MIRAMINI. He received his Ph.D. degree from the University of Melbourne in 2015. He is a lecturer at the University of Melbourne. His specific research

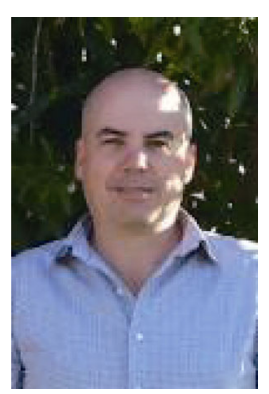

Bruce S. GARDINER. He received his Ph.D. degree from the University of Newcastle in 1999. $\mathrm{He}$ is a professor at Murdoch University. His research focuses

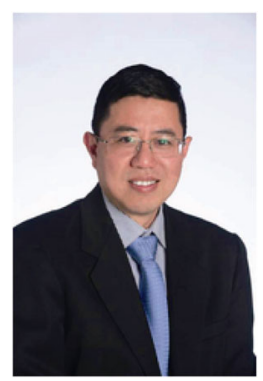

Lihai ZHANG. He received his Ph.D. degree from the University of Melbourne in 2009. He is an associate professor at the University of Melbourne. He has expertise interests include computational modelling of bone fracture healing, rehabilitation engineering, cartilage biomechanics, as well as non-destructive health assessment of structures and engineering reliability.

on integrating the physical, chemical, and biological processes defining biological systems. This is relevant to understanding diseases such as osteoarthritis, tendinopathy, colorectal cancer, and acute kidney injury.

in interdisciplinary research in both civil engineering (infrastructure asset protection, project management, and structural healthy monitoring) and biomedical engineering fields (orthopaedic biomechanics, mechano-biology, and cartilage lubrication). 